teit van het kapitaal en voor de normale instandhouding van de bedrijfshuishouding essentieele innerlijke evenwicht zoo goed mogelijk te hand haven.

Al deze overwegingen leiden tot de conclusie, dat ondernemers er wellicht den voorkeur aan zullen geven - voorzoover zij daartoe om voor de hand liggende redenen niet reeds verplicht zullen zijn - eerst na beëindiging van den oorlog hun kapitalisatie onder de oogen te zien, wanneer meer stabiele toestanden zullen zijn weergekeerd.

\title{
GRONDLIJNEN INKOMSTENBELASTING 1941
}

door J.J.M.H. Nijst †

\section{Voorwerp der belasting.}

De nieuwe inkomstenbelasting wordt geheven naar een reëel stelsel, in tegenstelling met de oude wet met haar bronnentheorie en haar ficties. Het nieuwe stelsel is als volgt uitgewerkt in art. 4:

(1) Voorwerp van de belasting is bij de binnenlandsche belastingplichtigen het zuiver inkomen, dat zij in een kalenderjaar hebben genoten.

(2) Onder zuiver inkomen wordt verstaan het in art. 5 omschreven onzuiver inkomen, verminderd met de onverrekende verliezen van vorige jaren en met de persoonlijke verplichtingen (artikel 16).

(3) Heeft de belastingplicht volgens Hoofdstuk I slechts gedurende een gedeelte van het kalenderjaar bestaan, dan treedt dit gedeelte (belastingtijdvak) voor het kalenderjaar in de plaats.

Daar dus belast wordt het zuiver inkomen over een kalenderjaar, zoodat dit eerst kan worden vastgesteld na het kalenderjaar, heeft in den loop van het jaar eene voorheffing plaats, welke verrekend wordt bij den definitieven aanslag.

Winst.

De winst van degene, die in zijn bedrijf of beroep regelmatig boekhoudt, wordt bepaald door vermogensvergelijking, waarbij de activa en passiva te waardeeren zijn volgens goed koopmansgebruik (Art. 9) Afschrijving is veroorloofd totdat de bedrijfswaarde is bereikt. Onder bedrijfswaarde wordt verstaan: de waarde, welke een verkrijger, bij overneming van het geheele bedrijf of beroep, zou toekennen aan het afzonderlijke activum, indien hij zou uitgaan van de overnemingswaarde van het geheel en voornemens zou zijn, de uitoefening van het bedrijf of beroep voort te zetten (art. 10 sub 2).

Voor de belastingplichtigen die niet boekhouden met jaarlijksche afsluiting, wordt de winst bepaald op het verschil tusschen de bruto-winst en de bedrijfs - of beroepskosten. Een en ander is geregeld in de artt. 12 $\mathrm{t} / \mathrm{m} 14$.

\section{Inkomen.}

De inkomsten worden beschouwd als te zijn genoten zoodra zij ontvangen of verrekend zijn, ter beschikking van den belastingplichtige gesteld zijn of rentedragend zijn geworden (Art. 15).

$\mathrm{V}$ an het inkomen mogen in mindering worden gebracht: 


\section{a. pensioenen;}

b. altijddurende renten, lijfrenten en andere periodieke uitkeeringen;

c. premiën voor lijfrenten ten hoogste $f 600$. - voor groep I, oploopend tot $f$ 1800. - voor groep III voor belastingplichtigen met aanspraak op aftrek voor meer dan 3 kinderen;

d. afschrijving op onroerende goederen.

Lijfrenten en andere al dan niet van het leven afhankelijke periodieke uitkeeringen aan bloed- en aanverwanten in de.rechte linie en in den tweeden graad der zijdlinie (broer, zuster, zwager en schoonzuster), de z.g. alimentatie-uitkeeringen, zijn niet voor aftrek vatbaar, tenzij zij de tegenwaarde voor een prestatie vormen.

Evenmin zijn voor aftrek vatbaar, de studickosten van meerderjarige kinderen, zoodat notarieele acten t.d.z. geen zin meer hebben.

De aftrek der premiën voor lijfrenten is zeer belangrijk en vormt een pré voor deze soort van verzekering boven die der kapitaalverzekering. Voor de laatste immers is in het geheel geen aftrek meer toegestaan (onder de oude wet I. B. 5\% van het zuiver inkomen met een maximum van $f$ 100.- ).

\section{Familie-vennootschap (Artt. 19 en 21).}

Tot het inkomen wordt mede gerekend - in tegenstelling met de Wet op de I. B. 1914 - de winst uit de vervreemding van niet tot het bedrijfsvermogen behoorende aandeelen in, of winstbewijzen van een vennootschap, waarvan het kapitaal geheel of ten deele in aandeelen is verdeeld en waarin de vervreemder een aanmerkelijk belang had. Een aanmerkelijk belang wordt aanwezig geacht, indien de vervreemder, hetzij alleen, hetzij te zamen met zijn verwanten, in den loop van de laatste vijf jaren voor meer dan een vierde gedeelte van het nominaal gestorte kapitaal middellijk of onmiddellijk aandeelhouder is geweest. Hierbij worden uitsluitend als verwanten beschouwd de echtgenoote, de bloed-en aanverwanten in de rechte linie en die in den tweeden graad der zijlinie.

De winst bij zoodanige vervreemding is het bedrag, waarmede de overdrachtsprijs na aftrek van de overdrachtskosten, de kosten vain de verkrijging te boven gaat, Deze winst wordt, op daartoe gedaan verzoek, afzonderlijk belast op den voet van artikel 48 (15 tot $37.5 \%$ ).

\section{Overdracht van bedrijf of beroep (Artt. 20 en 24).}

De winst, welke behaald is met of bij het overdragen of liquideeren van een bedrijf of beroep, wordt op daartoe gedaan verzoek afzonderijlk vastgesteld en op den voet van artikel 48 belast. De afzonderlijk vastgestelde winst is slechts belastbaar, voor zoover zij meer bedraagt dan $f$ 5.000. - of, bij overdracht van een gedeelte van een bedrijf, meer bedraagt dan een evenredig deel van $f$ 5.000. -

Onder winst, met de overdracht behaald, wordt verstaan het bedrag, waarmede de overdrachtsprijs, na aftrek van de overdrachtskosten, het bedrag van het zuivere bedrijfsvermogen te boven gaat.

Onder winst, bij liquidatie van het bedrijf behaald, wordt verstaan de opbrengst van de onderscheidene tot het bedrijfsvermogen behoorende zaken, na aftrek van de waarde welke, ten tijde van de vervreemding, aan deze zaken op den voet van artikel 10 dient te worden toegekend.

Opbrengst van roerend kapitaal.

Hiertoe worden mede gerekend: (art. 31)

m a b blz. 282 
liquidatie-uitkeeringen van vennootschappen, welker kapitaal geheel of ten deele in aandeelen is verdeeld, voor zoover $z \mathrm{ij}$ het gestorte kapitaal te boven gaan;

interessen, begrepen in kapitaalsuitkeeringen uit levensverzekering (de ingewikkelde berekening dezer interessen is neergelegd in artikel 33).

Bovenbedoelde liquidatie-uitkeeringen en interessen worden, op daartoe gedaan verzoek, afzonderlijk belast op den voet van artikel 48 .

Als liquidatie-uitkeeringen zijn te beschouwen de bedragen die uitgekeerd worden boven het nominale kapitaal. Ook indien men de aandeelen tegen hoogere koersen dan de liquidatie-uitkeering heeft gekocht, zal men I. B. over het surplus boven $100 \%$ moeten betalen, ofschoon men bij de liquidatie op deze aandeelen verlies lijdt.

Het is niet moeilijk in te zien, dat bij liquidatie van vennootschappen, wier aandeelen hoog genoteerd zijn, voor de koopers dier aandeelen bij de liquidatie aparte fiscale onbillijkheden kunnen ontstaan.

$\mathrm{Bij}$ uitreiking van aandeelen aan aandeelhouders zonder dat dezen de volle nominale waarde storten, wordt de nominale waarde als dividend beschouwd, voor zoover niet blijkt, dat storting heeft plats gevonden of zal plaats vinden.

Uit deze redactie van de eerste alinea van art. 32 valt o.i. af te leiden, dat bij afschrijving op aandeelen en latere bijboeking resp. uitkeering van nieuwe aandeelen, over deze uitkeering door aandeelhouders geen I. B. is te betalen, aangezien deze aandeelen immers vroeger volgestort zijn. Het Finantieel Weekblad voor den Fondsenhandel komt tot dezelfde conclusie:

"Wij zijn geneigd uit de redactie van de eerste alinea te concludeeren, dat een vennootschap, welke in het verleden b.v. $50 \%$ op haar kapitaal heeft afgeschreven, haar aandeelhouders - mits nog steeds de helft van het oorspronkelijke kapitaal uitstaat - gratis een nieuw aandeel kan uitkeeren, zonder dat de aandeelhouders daarvoor in de inkomstenbelasting aangeslagen zullen worden".

Geheele of gedeeltelijke teruggave van hetgeen op aandeelen is gestort, wordt als dividenduitkeering aangemerkt, indien en voor zoover er zuivere winst is, tenzij te voren het maatschappelijk kapitaal van het lichaam, dat de teruggave doet, door wijziging in de akte van oprichting, dienovereenkomstig is verminderd (art. 32, 2e lid).

\section{Inkomsten uit speculatie (art. 35),}

zijn aanwezig, indien:

onroerende zaken (zooals gronden, gebouwen) vrijwillig worden vervreemd binnen twee jaar nadat de vervreemder, door koop, ruil of andere overeenkomst onder bezwarenden titel, het recht op levering heeft verworven;

andere zaken (zooals effecten en koopwaren) vrijwillig vervreemd worden binnen een jaar nadat de vervreemder, door koop, ruil, of andere overeenkomst onder bezwarenden titel, een recht op levering heeft verworven.

Buiten beschouwing blijft de vervreemding van:

obligatiën ten laste van schuldenaren, die binnen het Rijk wonen of gevestigd zijn, tenzij aan zoodanige obligatiën, naast de vaste interessen, een aandeel in de winst of een optierecht op aandeelen is toegekend.

De zuivere inkomsten uit speculatie zijn slechts belastbaar, voor zoover 
zij, voor het kalenderjaar te zamen genomen, vijfhonderd gulden te boven gaan.

Is er geen batig saldo, doch een verlies uit speculatie, dan mag dit verlies niet op de andere inkomsten in mindering worden gebracht, en ook niet gecompenseerd worden met speculatiewinsten van andere jaren.

\section{Inkomsten bij liquidatie.}

Eene eigenaardige bepaling is die van art. 36, sub 2e. Deze rekent tot de bestanddeelen van het zuiver inkomen mede:

,hetgeen bij vervreemding van aandeelen in een vennootschap, waaivan het kapitaal geheel of ten deele in aandeelen is verdeeld en welke in liquidatie is getreden of waarschijnlijk binnenkort in liquidatie zal treden, ontvangen wordt boven het gemiddeld op de aandeelen gestorte kapitaal; deze bepaling geldt niet, indien de nieuwe verkrijger binnenlandsch belastingplichtige is, die bij de verkrijging niet in de uitoefening van een bedrijf of beroep heeft gehandeld".

In het Finantieel Weekblad voor den Fondsenhandel wordt deze bepaling als volgt gecommentarieerd:

„Volgens het bepaalde sub 2) zal het dus voortaan niet meer mogelijk zijn, aan belastingheffingen in verband met liquidatieuitkeeringen van meer dan $100 \%$ te ontkomen door een verkoop van de stukken vóór den aanvang van het fiscale jaar (z.g. bronnentheorie onder het oude stelsel). Wel kan men het heffingsobject van eigenaar doen veranderen, maar als de nieuwe bezitter voor onzen fiscus onbereikbaar is (doordat hij in het buitenland woont), komt deze bij den verkooper het hem toekomende deel van de bate opvorderen.

Overigens is de bepaling ,of waarschijnlijk binnenkort in liquidatie zal treden", er een, welke tegenover den belastingbetaler een bron van groote onzekerheid lijkt te creëeren. Immers, wie stelt de "waarschijnlijkheid van een aanstaande liquidatie" vast? Dat zal wel de inspecteur doen. En het bestaan van die waarschijnlijkheid zal wel aangenomen worden, als eenmaal het besluit tot liquidatie genomen is".

Buitenlandsche belastingplichtigen (Artt. 38-39).

Voorwerp van de belasting is bij buitenlandsche belastingplichtigen het binnenlandsch zuiver inkomen, waartoe gerekend worden:

le. binnenlandsche eigen onderneming en binnenlandsche arbeid. zijnde:

zelfstandig uitgeoefende beroepen. voor zoover binnen het Rijk uitgeoefend met behulp van een vaste inrichting of het vervullen van een dienstbetrekking, voor zoover dit binnen het Rijk geschiedt;

2e. Binnenlandsche vermogensbestanddeelen zijnde:

onroerende goederen,

schuldvorderingen, verzekerd door hypotheek,

rechten op een aandeel in de winst.

aandeelen, winstbewijzen en obligatiën van binnen het Rijk gevestigde vennootschappen, welker kapitaal geheel of ten deele in aandeelen is verdeeld, alsmede schuldvorderingen op zulke vennootschappen, indien de genieter hunner zuivere opbrengst bij de vennootschap een aanmerkelijk belang heeft in den zin van artikel 19.

m a b blz. 284 
De buitenlandsche belastingplichtigen worden aangeslagen in de gemeente door den Secretaris-Generaal van het Departement van Financiën te bepalen.

Tarief.

De belastingplichtigen - binnenlandsche zoowel als buitenlandsche worden ingedeeld in één van de tariefgroepen I, II en III.

Onder tariefgroep III vallen de belastingplichtigen, die aanspraak op kinderaftrek hebben.

Onder tariefgroep I of II vallen de belastingplichtigen, die geen aanspraak op kinderaftrek hebben. Daarvan vallen onder tariefgroep II:

1e. de gehuwde belastingplichtigen;

2e. de ongehuwde belastingplichtigen, die vóór 1 September van het kalenderjaar den leeftijd van 65 jaar hebben bereikt;

3e. de ongehuwde belastingplichtigen, die gehuwd geweest zijn en uit wier huwelijk een kind is geboren.

Onder tariefgroep I vallen de ongehuwde belastingplichtigen, die niet onder tariefgroep II of III vallen.

De belastingplichtige heeft aanspraak op kinderaftrek:

voor zijn eigen en aangehuwde kinderen en pleegkinderen, die minderjarig zijn en tot zijn huishouden behooren of met zijn toestemming tijdelijk elders verblijven voor het verkrijgen van onderwijs of voor opleiding voor een beroep;

voor zijn eigen en aangehuwde kinderen en pleegkidneren, die meerderjarig, doch nog geen 25 jaar zijn, en grootendeels op zijn kosten worden onderhouden en onderwijs genieten of worden opgeleid voor een beroep.

Aanspraak op kinderaftrek bestaat slechts voor kinderen, ten aanzien van wie aan alle eischen van het eerste lid is voldaan gedurende ten minste een derde gedeelte van het belastingjaar of belastingtijdvak.

Reeds meermalen werd verwezen naar het tarief op den voet van artikel 48. Dit tarief is gelijk aan het tarief voor de niet onder art. 48 vallende inkomsten, waardoor dus het geheele inkomen zal vallen onder het tarief voor het niet onder art. 48 vallende inkomen, met dien verstande, dat voor het laatste een minimum en maximum is vastgesteld, nl. 15 en $37.5 \%$.

Vermindering van het belastingbedrag (art. 51).

De Inspecteur houdt, door het belastingbedrag te verminderen, op daartoe gedaan verzoek, rekening met op den binnenlandschen belastingplichtige drukkende buitengewone lasten, welke op diens vermogen om belasting te betalen een aanmerkelijken invloed hebben. De inspecteur stelt de grootte van de vermindering naar zijn vrij en redelijk goedvinden vast.

Als buitengewone lasten worden o.a. aangemerkt:

uitgaven tot voorziening in het levensonderhoud van eigen en aangehuwde kinderen en pleegkinderen, voor wie geen kinderaftrek wordt genoten, en van andere bloed- en aanverwanten in de rechte linie en in den tweeden graad der zijdlinie; eveneens groote uitgaven voor ziekte, sterfgeval etc.

Van een aanmerkelijken invloed op het vermogen om belasting te betalen is eerst dan sprake, indien de buitengewone lasten meer bedragen

m a b blz. 285 
dan $10 \%$ van het zuiver inkomen, nadat dit verminderd is met 10 ten honderd, doch met niet meer dan $f 1200$ voor elk kind waarvoor aanspraak op kinderaftrek bestaat.

Een voorbeeld moge deze clausule toelichten.

Heeft een belastingplichtige een zuiver inkomen van b.v. $f$ 40.000.en aanspraak op kinderaftrek voor drie kinderen, dan is er sprake van buitengewone lasten, zooals hierboven bedoeld, indien deze méér bedragen dan:

$10 \% \operatorname{van}(f 40.000 .-\min f 3600 .-)$ 36.400. - of $f 3.640 .-$

Verrekening van de voorheffingen bij den aanslag (art. 53).

Met den aanslag worden verrekend:

de dividendbelasting, betrekking hebbende op in het onzuiver inkomen (artikel 5, lid 1) begrepen opbrengsten;

de ingehouden loonbelasting:

de voor het kalenderjaar of het belastingtijdvak opgelegde voorloopige aanslagen.

Handhaving der wet op de I. B. 1911 .

De bepalingen dezer wet blijven gehandhaafd ten aanzien van: de regeling der aanslagen (art. 70)

bezwaren tegen den aanslag

navordering

verhooging van den aanslag

geheimhouding en d.g.

strafbepalingen

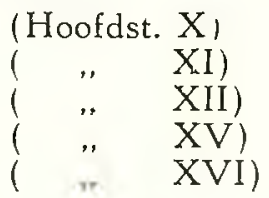

Overgangsbepalingen.

Artikel 60 bevat nog enkele overgangsbepalingen. Volgens dit artikel kan worden bepaald, dat bij het inkomen over 1941 een deel van het inkomen over 1940 wordt gevoegd. In het „Invoeringsbesluit Inkomsten belasting 1941" is dit als volgt geregeld:

„Overtreffen de zuivere opbrengsten van eigen onderneming en van arbeid in het kalenderjaar 1940 die in het kalenderjaar 1941, dan wordt voor de berekening van het zuiver inkomen in het kalenderjaar 1941, het verschil, voor zoover het $f 1000$. - te boven gaat, geacht op den 1sten Januari 1941 te zijn genoten".

De bedoeling dezer bepaling is duidelijk. De inkomsten van 1940 kunnen niet meer tot grondslag dienen voor een aanslag I. B. over 1940. Dengenen, die in 1940 veel hoogere inkomsten hebben genoten dan over 1941, zou daardoor een voordeel in den schoot vallen, dat de fiscus zich echter niet wil laten ontnemen. Vandaar de bepaling om de meerdere inkomsten van 1940 boven 1941 onder aftrek eener marge van $f$ 1000. van 1940 naar 1941 over te hevelen.

Tenslotte laten wij nog volgen de voornaamste invoeringsbepalingen, ontleend aan het

Invoeringsbesluit Inkomstenbelasting 1941.

1. Over 1941 zal een voorloopige aanslag worden opgelegd op basis der inkomsten 1940, opgevat en berekend conform de bepalingen der nieuwe I B. maar met uitzondering van de inkomsten uit speculatie. 
2. Indien aannemelijk is, dat de inkomsten van 1941 aanmerkelijk lager zullen zijn dan die van 1940, kan de voorloopige aanslag naar dat lager inkomen worden opgelegd.

3. In mindering van den voorloopigen aanslag 1941 wordt gebracht $1 / 3$ van den aanslag voor het belastingjaar 1940/41, die nog geheven werd onder vigueur der oude wet op de I.B. 1914.

4. Tegen den voorloopigen aanslag kan niet worden opgekomen.

Wij vertrouwen door het aangeven van bovenstaande grondlijnen het beeld onzer nieuwe inkomstenbelasting voldoende duidelijk te hebben geschetst.

\section{DE ONTWIKKELING VAN HET NEDERLANDSCH- DUITSCHE BETALINGSVERKEER (Slot) ${ }^{1}$ )}

door Drs E. E. Harmsen en Drs L. Vrind

\section{Geblokkeerde Markenbelasting.}

Tegelijk met de verzachtende bepalingen, die in het NederlandschDuitsch belastingverkeer werden aangebracht, trad op 1 November 1940 in werking het Geblokkeerde Markenbelastingbesluit 1940.

De geblokkeerde markenbelasting werd geheven van de tegenwaarde, verkregen bij vervreemding of delging van beleggingen of vorderingen, voor zoover deze op 1 November 1940 eigendom waren van Nederlandsche ingezetenen, uit het Duitsche Rijk naar Nederland. $Z_{\mathrm{ij}}$ werd geheven door inhouding bij uitbetaling.

Onder beleggingen en vorderingen verstaat het Besluit:

1. in het Duitsche Rijk gelegen onroerende goederen of op zulke goederen gevestigde rechten;

2. aandeelen en andere deelnemingen in, alsmede rechten op een aandeel in de winst van ondernemingen, die in het Duitsche Rijk gevestigd ziin;

3. al dan niet door effecten vertegenwoordigde schuldvorderingen op Duitsche publiekrechtelijke lichamen dan wel op particuliere personen en lichamen, die in het Duitsche Rijk wonen, gewoonlijk verblijven of gevestigd zijn;

4. andere zaken, door den Secretaris-Generaal van het Departement van Financiën gelijkgesteld met onder 1 tot en met 3 genoemde zaken, zulks in overeenstemming met de Duitsche regelingen betreffende het overmaken van kapitalen.

Onder beleggingen en vorderingen in den zin van het Besluit zijn niet begrepen:

1. zaken, welke het eigendom zijn van personen en lichamen, die in Duitschland wonen, gewoonlijk verblijven of gevestigd zijn;

3. de Dawes - en Young leeningen en obligaties ten laste van de voormalige republiek Oostenrijk;

3. de ,Answanderer-Sperrmarken;

4. andere zaken, die door den Secretaris Generaal van het Departement van Financiën met die, genoemd onder 2 en 3 gelijkgesteld zijn. Zulke zijn: obligatie's ten laste van de voormalige Tsjecho-Slowaaksche republiek en obligatie's ten laste van de voormalige vrije stad Danzig.

I) I In de Juni-aflevering 1941, blz. 215 ev.; II in de Juli-aflevering, blz. 243 ev. 